\section{HONOURS, AWARDS, APPOINTMENTS}

New Head for Peninsula

Professor Christopher Tredwin has been named as the Head of the new Plymouth University Peninsula School of Dentistry. Professor Tredwin will lead the School from its inception in September 2012. Professor Tredwin is currently Director of Clinical Dentistry and Professor of Restorative Dentistry at the Peninsula College of Medicine and Dentistry and leads his own practice in London.

\section{Honorary Fellowship}

Dr Lester Ellman has received an honorary fellowship from the Faculty of General Dental Practice (FGDP), part of the

Royal College of Surgeons of England, in recognition of his contributions to the dental profession. Dr Ellman is the founder of LR Orthodontics and The Dentistry Business; the $L R$ appliance has revolutionised the procedure for straightening anterior teeth, enabling patients to wear the appliance for as little as 14 hours a day, including at night.

\section{Eight hundred and seventy diplomas}

Over 30 diplomas in Dental Postgraduate Studies were awarded this year by Bristol University Open Learning for Dentists, bringing a total of 870 awarded since 1994. Twelve courses in dental related topics are available each year and students receive a diploma when they have successfully completed three courses.

\section{Scottish Dental Lifetime Achievement}

Professor William Saunders has received the first ever Scottish Dental Lifetime Achievement Award, paying tribute to his commitment to the dental industry in Scotland. Professor Saunders is the former dean of Dundee Dental School and chair of the Dental Schools Council. He received his award during a drinks reception at the inaugural Scottish Dental Show in May.

\section{ADAM Awards}

The Association of Dental Administrators and Managers (ADAM, formerly the BDPMA) held the first ever ADAM Awards in Harrogate in May. Nicki Rowland was crowned Practice Manager of the Year; Christine Ferguson Administrator of the Year; and Melissa White was awarded Treatment Coordinator of the Year.

\title{
DENTAL PATIENTS ARE LARGELY SATISFIED
} WITH SERVICES

On 29 May the Office of Fair Trading (OFT) published an extensive report into the UK dental market. Overall, the OFT found that 'dental patients are largely satisfied with the services provided by their dentist. ${ }^{1}$

Despite this finding, widespread media coverage focused on the claim by the OFT that 'around 500,000 patients each year may be provided with inaccurate information by their dentist regarding their entitlement to receive particular treatments on the NHS. ${ }^{1}$ The OFT report also criticised the current NHS contract, which it said limited competition; the current complaints procedure; and the GDC's delay in implementing the 'requisite reforms' to end restrictions on direct patient access to dental hygienists and technicians.

The British Dental Association (BDA) commented that the OFT's report fails to take a practical


complexities and realities of dental care. The BDA also expressed disappointment at the way the report has been portrayed, arguing that the OFT's own acknowledgement of the high levels of patient satisfaction with dental care appears to have been set aside in favour of headline-grabbing statistics.

'Dentistry is not a commodity; it's the delivery of healthcare to real patients. Failing to understand that serves neither dentists nor patients well, said Dr Susie Sanderson, Chair of the BDA's Executive Board. 'Also crucial is the development of a new dental contract already underway in England.'

The British Dental Health Foundation (BDHF) acknowledged that parts of the report have validity but also highlighted some shortcomings.

'This report should not be taken as cure-all for the future of dentistry in the UK and if taken in isolation it does not deliver a satisfactory solution for the patients or the dental health profession, said Dr Nigel Carter, BDHF Chief Executive.

The full report can be accessed online. ${ }^{1}$

Office of Fair Trading. Dentistry: an OF market study. May 2012. www.oft.gov. uk/shared_oft/market-studies/Dentistryl OFT1414.pdf (Accessed 8 June 2012). 